\title{
3D Printing Part 2: A Literature Review Of 3D Printing Materials in Dentistry
}

\author{
Adam Nulty ${ }^{1 *}$ \\ 1 University of Leeds, Woodhouse Lane, Leeds, LS2 9JT; dnabn@leeds.ac.uk \\ * Correspondence: dnabn@leeds.ac.uk
}

\begin{abstract}
Introduction: The current generation of 3D printers are lighter, cheaper, and smaller, making them more accessible to the chairside digital dentist than ever before. 3D printers in general in the industrial and chairside setting can work with various types of materials including, metals, ceramics, and polymers. Evidence presented in many studies show that an ideal material used for dental restorations is characterised by several properties related to durability, cost-effectiveness, and high performance. This review is the second part in a 3D Printing series that looks at the literature on material science and applications for these materials in 3D printing as well as a discussion on the potential further development and future evolution in 3D printing materials. Conclusions: Current materials in 3D printing provide a wide range of possibilities for providing more predictable workflows as well as improving efficiency through less wasteful additive manufacturing in CAD/CAM procedures. Incorporating a 3D printer and a digital workflow into a dental practice is challenging but the wide range of manufacturing options and materials available mean that the dentist should be well prepared to treat patients with a more predictable and cost effective treatment pathway. As 3D printing continues to become a commonplace addition to chair side dental clinics, the evolution of these materials, in particular reinforced PMMA, resin incorporating zirconia and glass reinforced polymers offer increased speed and improved aesthetics that will likely replace subtractive manufacturing milling machines for most procedures.
\end{abstract}

Keywords: 3D printing; intraoral scanners; digital dentistry; trueness; precision; accuracy; history

\section{Introduction}

The current generation of 3D printers are lighter, cheaper, and smaller, making them more accessible to the chairside digital dentist than ever before. 3D printers in general in the industrial and chairside setting can work with various types of materials including, ceramics, polymers as well as metals. Evidence presented in many studies show that an ideal material used for dental restorations is characterised by several properties related to durability, cost-effectiveness, and high performance.[1] The range of materials used for provisional dental restorations should be non-toxic, biocompatible, inert, reasonably inexpensive, and aesthetic with change in colour or appearance after fabrication and complete resin polymerisation through curing.[2] Furthermore, the material for dental restoration should be easy to manipulate, dimensionally stable under all conditions through sufficient strength and resilience, and easy to polish and repair. The material also needs to be chemically stable in the oral cavity by being insensitive to water sorption and dehydration; hence lead to a lack of expansion, shrinkage, or cracking.[3]

\section{Current Materials}

There is currently a wide range of materials used in the dental sector of 3D printing. These can be summarised in Table 1 below with a more in depth description of the most widely used materials specifically used in dentistry. 
Table 1. A list of materials used with 3D printing in dentistry grouped by manufacturing technology

\begin{tabular}{cc}
\hline Printing Technology & Materials Available \\
\hline Polyjet Printing & Photopolymers \\
\hline Multi-Jet Printing & Plastics, Ceramics and Metals \\
\hline Fused Deposition Modelling (FDM) & $\begin{array}{c}\text { ABS, Polypropylene, Polycarbonates, Pol- } \\
\text { yesters }\end{array}$ \\
\hline Selective Laser Sintering (SLS) & $\begin{array}{c}\text { Plastics, Ceramics and Metals } \\
\text { Selective Laser Melting (SLM) }\end{array}$ \\
\hline SLA / DLP & Photopolymers, Plastics and Ceramics \\
\hline
\end{tabular}

\section{i) Current Long Term 3D Printed Ceramics and Current Restorative Resins}

Considering the requirements for a non-toxic, biocompatible, and inert material, the range of materials available for use in $3 \mathrm{~d}$ printed dental restorations are limited. On the other hand, the fabrication process of CAM milling manufacture requires high temperatures to convert ceramic materials into restorations suitable for placement in the mouth. Currently, ceramic 3D object is extremely limited in dentistry as it is manufactured by binding fine ceramic powder to a binder where a traditional process of ceramic restorations such as lithium dislocate is ground from ceramic blocks in chairside setting.[4] Ceramic materials have several ideal properties for use in long termdental restorations such as lead-free, non-toxic, and watertight; however, ceramic is a complex material to design a $3 \mathrm{D}$ object as it requires a number of considerations in design due to the different structural changes the object may undergo during the finishing process. The current $3 \mathrm{D}$ printers developed for dental applications are limited in their use of metals and ceramic materials to produce provisional dental restorations and are variable in the effect of print direction and accuracy.[5]

Most of the 3D printing materials used in dental restorations are polymers. Unlike the ceramics and metals, the chemical and physical properties of polymers are characterised by elasticity and tensile strength, which potentially provide high-performance and durability features required for use as a dental restorative material.[3] In orthodontic practice, 3D printing technologies have produced a wide array of prosthetics for dental restorations using polymer materials such as denture bases, artificial teeth, temporary crowns, bridge and crown facings, and implants. [6,7] Studies have reported the use of polymers in 3D printing technologies for dental applications, including implant fixture construction and intervention, maxillofacial reconstruction [8], metal bridges.[9] Other stud- 
ies have reported the application of 3D printing in manufacturing dental prosthetics used in dentistry as orthodontic appliances [10] as well as the fitting surfaces and the frameworks of removable partial dentures.[11]

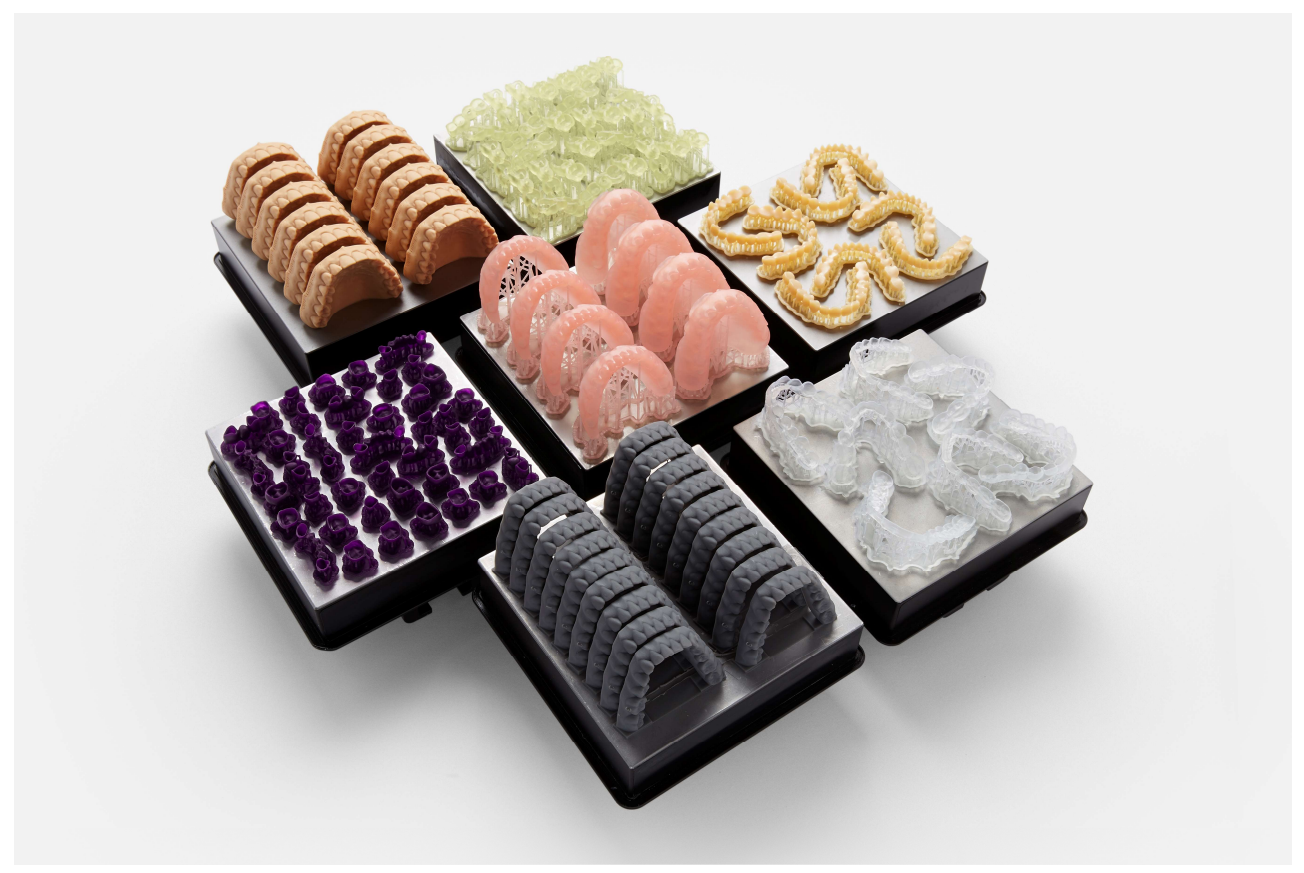

Figure 1. A Variety Of Dental Resin Materials[46]

The majority of polymers used as dental restorative materials such as resins are prepared using the methods of addition polymerisation, and in particular SLA \& DLP technologies. In dentistry, most dental resins are based on methacryrates due to relatively easy processing, costs, and aesthetics. Denture base materials are often supplied in either gel or powder-liquid form.[3] The powder consist of acrylic or copolymer heads, an initiator like benzoyl peroxide, pigments (mercuric sulphide, cadmium sulphide, or dyes), and opacifiers where one the most effective being titanium dioxide. They also contain dyed synthetic fibres to stimulate the blood vessels underlying the oral mucosa, plasticisers, and inorganic particles such as glass fibres and beads or zirconium silicate.[12] Conversely, the liquid is composed of a monomer particularly methyl methacrylate, an accelerator, inhibitor, plasticiser, and across-linking agent. For the gel form of denture base materials, it basically contains all the components of particle-liquid form but lacks chemical accelerators. The dental materials in gel form are commonly stored in the refrigerators since the material's shelf life are significantly affected by the amount of inhibitor present and its storage temperature.[13] 


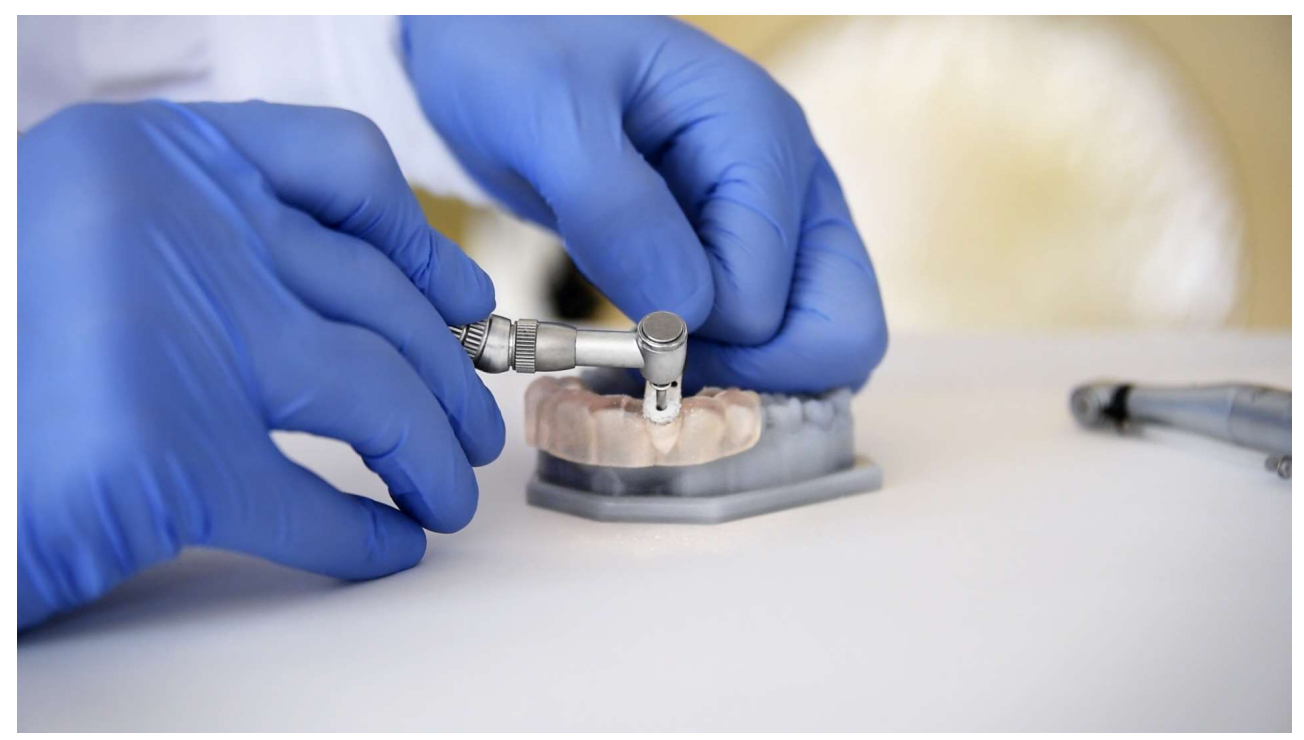

Figure 2. Surical Guides are an example of the use of biocompatible resins used in dentistry[46]

The current dental restorative materials applied in dentistry encompass photosensitive resins, as a polymer or particle-reinforced composite. Biocompatible polymers are widely used in dentistry for general restorative procedures and the most common 3D printers available to use chair side accommodate similar polymer based $3 \mathrm{~d}$ printing resins. 3D printed indirect dental restorations may involve either particle-reinforced composites, which are similar to the direct restorative composites, or fibre-reinforced composites.[13] The particle-reinforced composites are typically produced in the dental laboratories to improve the materials physical and mechanical properties such as density, elasticity, and strength using polymerisation process through heat and pressure. For the fibre-reinforced fibreglass composites, they are produced using the same technology of making fibreglass sports equipments where fibre mesh is embedded in polymers.[14]

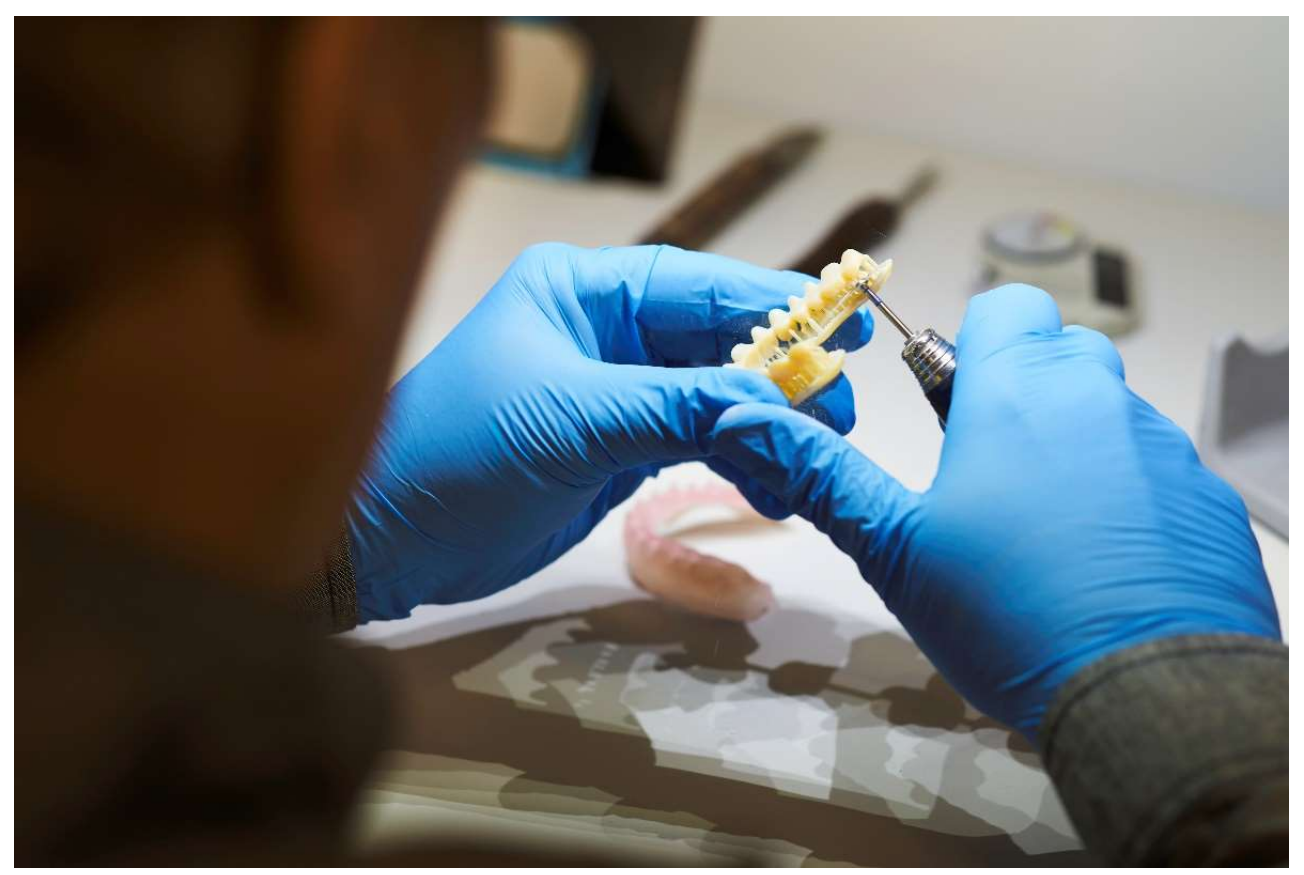

Figure 3. Temporary 3D Printed teeth for use in a 3D printed denture[46] 
Dental resin-based composites are structures comprising a highly cross-linked matrix reinforced by a dispersion of glass ceramics and resin filter particles and/or short fibres.[2,13] Many of these resinbased composites are now highly aesthetic with excellent translucency; hence, becoming the most popular of the aesthetic or tooth-coloured filling materials for use in dental clinics.[15] The resin materials can also be made in various consistencies by altering the glass particle size and consistency as well as the filler content, which allows easily manipulation and moulding to a tooth shape that is long lasting and durable once polymerised and full cured.[16] Polymeric resins are increasingly being used in dentistry for dental restorations, replacing tooth structure and missing tooth. One advantage of these polymeric resins is their ability to bond with other resins, directly to the tooth structure or to other restorative materials such as amalgam. For example, a denture base with attached denture could be used to restore chewing ability when all teeth are missing. Most of these restorative and prosthetic applications are based on photo-polymerisable methacrylate resins.[2,14]

Several manufacturers are working on 3D printed resin versions of these same polymers for use in orthodontic clear aligners, denture bases, artificial teeth, surgical guides etc. As one of the largest vendor of 3D printing materials, Stratasys has been reported to have developed various types of dental 3D printing materials such as wax deposition modelling (WDM) and polyjet materials.[13] The WDM are used to manufacture extremely accurate diagnostic wax-ups, paired with a removable wax-blend materials referred as TrueSupport, which can be removed at relatively low temperatures. It has been reported that Stratasys 3D printers using WDM produce the most accurate waxups in the dental industry. Additionally, other 3D printing benefits of WDM include the ability to directly produce from digital files, no waste disposal issues, high-quality casting with minimal postprocessing procedures, and TSCA-registered for safety.[17]

\section{iii) Metals}

A material commonly used in dentistry is metal which is popular for the use in strengthening restorations or incorporation into frameworks. This has led to these materials to be researched and developed for additive manufacture, mainly via selective laser sintering (SLS). Due to favourable levels of strength, cobalt-chromium and titanium metals have seen the most developments.[18]

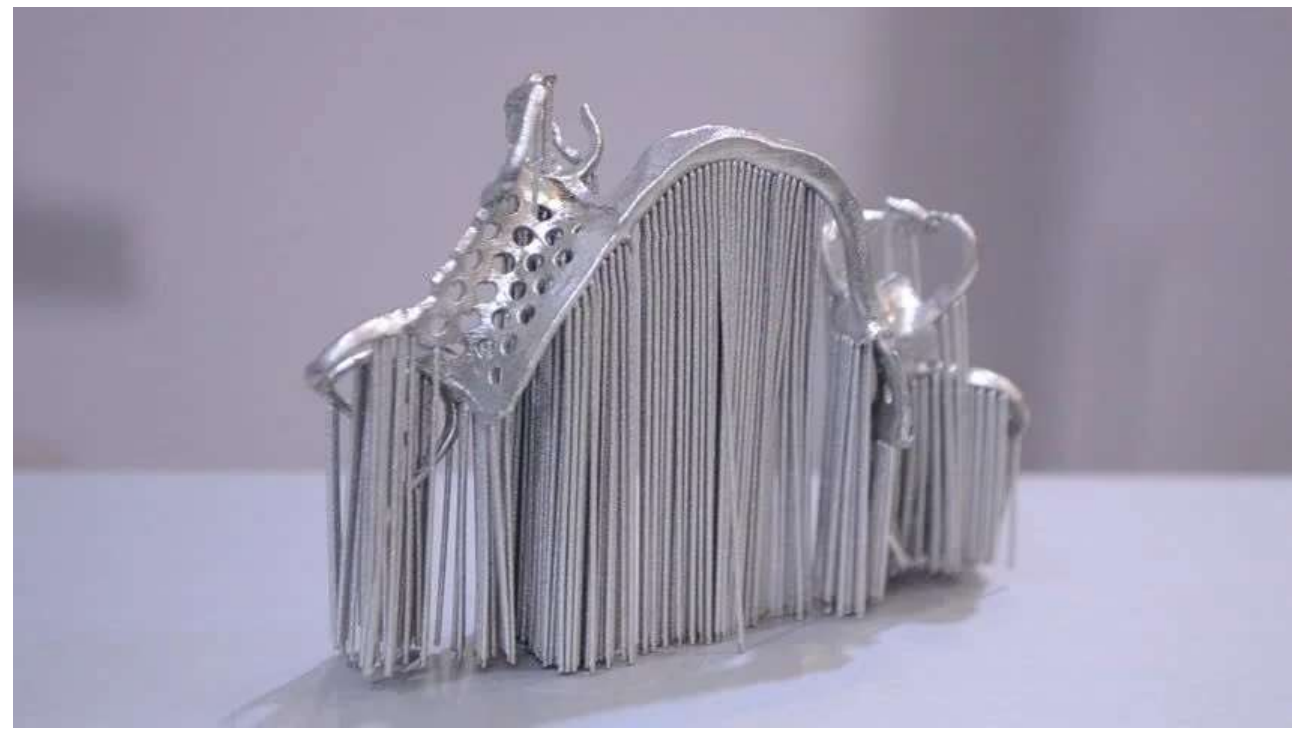

Figure 4. SLS 3D printed metal partial denture framework in $\mathrm{CoCr}$ 


\section{iv) PEEK \& Nylon}

A 3d printing material of recent development for use in dentistry has been the polyether materials such as Polyether Ether Ketone (PEEK) and Nylons for use in frameworks, to strengthen other materials and in 3D printed flexible dentures. These materials have a higher melting point and as such require an Fused deposition modelling (FDM) printer with a high temperature, high precision nozzle tip.[19]

Like most $3 \mathrm{~d}$ printing applications, the benefits of using $3 \mathrm{~d}$ printed metals, peeks and nylons are many. Faster processing, less wasteful additive rather than subtractive manufacture as well as less manual labour and labour intensive processes. However, there are limitations to the fabrication of restorations and frameworks using additive manufacturing. Rather than a homogenous structure, fabrication of these materials with $3 \mathrm{~d}$ printing may result in porous structures which are inherently susceptible to staining, fracture and cracking.[19,20]

\section{Proposed Materials for Exploration:}

\section{i) Reinforced Composites}

The most popular and commonly used polymeric denture base material within dentistry is known as polymethylmethacrylate (PMMA). It is an extremely stable, transparent thermoplastic that does not de-colour in the presence of UV light, and exhibits remarkable ageing properties.[16] PMMA is a resin-based material that has been used in 3D printing technologies to fabricate dental provisional restorations to protect oral structures such as pulpal tissue from thermal sensitivity, physio-mechanical pain, and bacterial contamination.[2] For the purposes of implant treatment, larger framework restorations and dentures, these PMMA 3D printed prostheses require high tensile and flexural strengths to be adequate for long term use. This underscores the importance of using materials with sufficient wear resistance and mechanical strength in orthodontic clinical practice.[12]

Conventional self-polymerising PMMA-based resin materials have been shown with a number of limitations, including high polymerisation shrinkage, water sorption and heat generation, and thus there are concerns that these limitations may pass over to 3D printed PMMA restorations.[21] Conventional fabrication using PMMA with a mixture of self-polymerising powder and liquid requires longer cure times than would be practical for a chairside setting.[21] Considering one of the advantages of digital manufacturing is speed and efficiency, the use of $3 \mathrm{D}$ printed resin materials need to be both a viable alternative to conventional resin materials to support long-term dental applications in orthodontic practice.[14]

In particular, the recent advancements in routine dental practices with chairside CAD/CAM dentistry such as 3D printed prosthodontic treatments have been driven by the introduction of new processing technologies and dental materials. A number of dental laboratory processes can be used to fabricate either fixed or removable dental prostheses such as crowns using a variety of dental materials.[22] The advancement of both casting gold alloys and the associated accuracy in dental casting technologies has contributed to the persisting use of these prostheses.[23] New dental ceramic materials such as glass ceramics as well as lithium silicates/disilicates and zirconia-based ceramics have been successfully used by CAD/CAM enabled dental clinics with several studies showing excellent long term success rates over ten years. [24] Therefore any new 3D printing material must be equal to or show alternate benefits to these well studied materials as well as biosafety and excellent aesthetics.[25] 


\section{ii) Zirconia based materials}

Among all dental ceramics, zirconia is the most popular biomaterial of choice in contemporary dental restorations in dentistry, particularly as a structural material for crowns, bridges, inserts, and implants.[24] Zirconia (zirconium dioxide) provides optimum properties of a material for dental use, including tensile strength, fatigue resistance, and outstanding wear properties and biocompatibility.[26] Zirconium (Zr) has similar biochemical properties to Titanium (Ti) metal, in which both are commonly used in implant dentistry as they lack the capacity to hinder the bone forming cells (osteoblasts) to facilitate osseointegration.[27] Although zircornia is characterised as useful dental biomaterial, zirconia based materials present several challenges in its dental practice applications as they are difficult to adhere to compared to other glass ceramics and composite materials.[26]

The adhesive bond between ceramics and resin-based materials comes is through a combined micro mechanical and chemical interaction across the contact interface. The overall bond strength is highly dependent on the surface treatment and surface energy through silination of the glass ceramic to increase its wettability.[26,28] It has been reported that, of all types of acid-resistant bonding for ceramic dental restorations like glass ionomer (GI) and hydrophobic phosphate monomers containing 10-methacryloyloxydecyl-dihydrogen-phosphate (MDP) monomer, resin-based composite systems are the most popular and effective for high bond strength between a wide range of materials. $[29,30]$

Several studies have shown that quality and the durability of the micro-mechanical and/or chemical bond between glass ceramic and resin based materials has a high impact on the long term success rates of the prosthesis placed.[31,32] The non-reactive or acid-resistant surface of zirconia often poses a major concern related to poor adhesion or reduction of bond strength to other substrates.[32]

Furthermore, chemically polymerised materials available for provisional dental restorations using either PMMA or resin-based composites have unique properties, which are depend on the composition of the chemical monomer.[33] It has been demonstrated that different monomers vary in their chemical effects such as polymerisation shrinkage, exothermic reactions, marginal fit, colour stability, periodontal responses and fracture strength.[26] The fracture strength of the provisional restorative materials relates to the mechanical properties.[34]

In terms of mechanical strength and physical properties, the superiority of zirconia has largely been utilised for aesthetic dental restoratives, including crowns and bridges.[35] Zircornia is typically veneered with feldspathic porcelain due to its insufficient translucency; nevertheless, the strength of the veneering porcelain has been indicated as inadequate in its function as a dental restorative.[24] The main clinical feature of failed zirconia based restorations has been reported to be due to the wear and fracture of the laminated porcelain layer.[36] However 'full contour' zirconia based restorations without a porcelain layer have been shown to be problematic in some cases with wear of the opposing teeth causing gross fracture and ultimate total failure of the prosthesis.[26,37]

In a study by Park et al, wear resistance of the 3D printed resin material was compared to the milled and the conventional self-cured resin materials opposing zirconia and metal antagonists (CoCr alloy).[38] The basic component of all the three resin materials was similar but the study found differences in wear patterns between the materials and the casted cobalt-chromium ( $\mathrm{CoCr}$ ) alloy denture abraders. This study suggested that the properties of PMMA-based resin materials could vary according to the fabrication methods used. When CoCr alloy metal abrader was applied in the 3D printed resins, cracks occurred as well as separation of the inter-layer bonds between layers of resin. This occurs as the bond that occurs between layers is weaker than the bond formed between each consecutive 3D printed layer.[38] The results of this study indicated that the clinical use of 3D printing technologies presents a more convenient and promising technique fabricating provisional dental restorations and increase productivity in dentistry.[38] 


\section{Limitations}

Another limitation of 3D printed materials occurs as the surface of these materials are vulnerable to oxygen inhibition. As these prosthesis could then be subject to immediate exposure to saliva through direct patient contact, the long term mechanical strength and long term colour stability could be reduced.[2] Conversely, blocks used in CAD/CAM systems are constructed with the optimum polymerisation conditions in place for complete and uniform polymerisation without inhibition. Studies have shown that provisional dental restorations fabricated from materials in CAD blocks (monomethacrylate or dimethacrylate) have superior mechanical properties compared to those fabricated by both conventional and 3D printing technologies.[1,14]

A meta-analysis study by Astudillo-Rubio et al.[39] found no significant difference between monomethacrylates (PMMA) and dimethacrylates (PEMA) in regard to their fracture strength, the ability to prevent the propagation of cracks. However, both groups vary according to the way they interrupt the cracks propagation where dimethacrylate materials are less susceptible to crack propagation in the presence of water.[12,39] PEMA may therefore be a potential avenue for increased strength in future 3D printing materials which are less brittle than PMMA based materials[1,14] Over time, water absorption by non-cross-linked polymers subsequently weakens the material, which gradually diminishes the plasticising effect and the associated fracture toughness.[2]

Polymethylmethacylate (PMMA) resin remains one of the most commonly used materials for provisional dental restorations within dentistry due to greater flexural strength compared to PEMA. It has been reported that provisional dental restorations based on PMMA have many advantages including, colour stability, aesthetics, marginal fit, tensile and strength. Furthermore, a number of PMMA dental models can be easily fabricated, polished, and repaired using the 3D printers, which not only reduces the production time but also allows multiple 3D copies to be produced without altering the dental anatomy.[36,37,38] However, as the studies above have shown, the flexural strength of PMMA decreases gradually over time, meaning current formulations may be inadequate for use as long term restorations. Studies have reported that the use of PMMA resin materials in dental restoration cause irritation of oral tissues, have low wear resistance, and high volume shrinkage due to leaching of the free monomer.[21,38]

\section{Future developments with graphene and fibreglass reinforcement}

Based on evidence presented in meta-analysis by Astudillo-Rubio et al.,[39] several studies reported that the structure of the provisional dental restorations could be reinforced with fibreglass or graphene to improve their flexural strength and fracture toughness and this could be a possible route for $3 \mathrm{D}$ printer materials to provide more suitable long term restorations $[42,43]$ These strengtheners may not make the material completely immune to fracture, but may simply change the fracture path to allow easy repair of chips rather than a full catastrophic fracture leading to ultimate failure of the prosthesis.[39] Therefore, if 3D printing resin can incorporate graphene or polyethylene fibres into the polymer matrix, this should result in a stronger restoration.[44,45] Hamza, Johnston and Schricker[43] assessed this reinforcement effect following the addition of $1 \%$ of the polyhedral oligomeric silsesquioxane (POSS). The results indicated that "the reinforcement effect of POSS on flexural strength depended on the brand", suggesting that particular chemical composition of the provisional materials determines the ability of POSS to improve their mechanical properties, which may mean that some $3 \mathrm{~d}$ printer resin brands may perform better than others even if based on similar material technology.[43]

\section{Conclusion}

Current materials in 3D printing provide a wide range of possibilities for providing more predictable workflows as well as improving efficiency through less wasteful additive manufacturing in $\mathrm{CAD} / \mathrm{CAM}$ procedures. Incorporating a $3 \mathrm{D}$ printer and a digital workflow into a dental practice is challenging but the wide range of manufacturing options and materials available mean that the 
dentist should be well prepared to treat patients with a more predictable and cost effective treatment pathway. As 3D printing continues to become a commonplace addition to chair side dental clinics, the evolution of these materials, in particular reinforced PMMA, resin incorporating zirconia and glass reinforced polymers offer increased speed and improved aesthetics that will likely replace subtractive manufacturing milling machines for most procedures.[44,45]

Literature Search Details: The literature chosen was selected with eligibility criteria between the dates 1970 to the date the search was made on the 05/03/2019. The search was limited to;

- English language articles.

- Dental Literature

- Text searching for '3d AND printing OR print', 'additive AND technology', 'rapid AND prototyping', '3d printing AND materials', ‘3d printing AND accuracy', ‘3d print AND accuracy', 'history AND 3d AND printing', 'development AND 3d AND printing'.

- A manual search of the articles found and their respective references for other articles and reviews was also made.

Author Contributions: Author: Adam Nulty; Contributed to conception, design, data acquisition and interpretation, drafted and critically revised the manuscript. The author gave his final approval and agrees to be accountable for all aspects of the work.

Funding: This research received no external funding

Conflicts of Interest: There is no conflict of interest to declare. The author has no financial interests or connections, direct or indirect, that might compromise the perception of the authors as impartial. There is no financial interest that includes commercial or other sources of funding for the author or associated department(s) or organisation(s), personal relationships, or direct academic competition.

\section{References}

1. Rayyan, M. M., Aboushelib, M., Sayed, N. M., Ibrahim, A., \& Jimbo, R. (2015). Comparison of interim restorations fabricated by CAD/CAM with those fabricated manually. J Prosthet Dent, 114 (3), 414-419. doi: 10.1016/j.prosdent.2015.03.007.

2. Balkenhol, M., KoÈhler, H., Orbach, K., \& WoÈstmann, B. (2009). Fracture toughness of cross-linked and non-cross-linked temporary crown and fixed partial denture materials. Dent Mater, 25(7), 917-928. doi: 10.1016/j.dental.2009.01.099.

3. Vaidyanathan, T. K., Vaidyanathan, J., \& Arghavani, D. (2016). Elastic, viscoelastic and viscoplastic contributions to compliance during deformation under stress in prosthodontic temporization materials. Acta biomaterialia odontologica Scandinavica, 2(1), 108-117. doi:10.1080/23337931.2016.1219664.

4. Elizabeth, B. (August, 2014). 3D Printed Ceramics. Web. Retrieved on May 7, 2019 from http://www.materialise.com/blog/3dprinted-ceramics/

5. Brenes C, Renne W, Tolbert T, Fantaski L. Effect of Print Angulation on Surface Roughness of 3D-Printed Models. Compend Contin Educ Dent. 2020 Nov;41(10):e1-e4. PMID: 33350846.

6. Oberoi, G., Nitsch, S., Edelmayer, M., Janjić, K., Müller, A. S., \& Agis, H. (2018). 3D Printing-Encompassing the Facets of Dentistry. Frontiers in bioengineering and biotechnology, 6, 172. doi:10.3389/fbioe.2018.00172.

7. Stewart, M., \& Bagby, M. (2018). Clinical aspects of dental materials: Theory, practice, and cases. Philadelphia: Wolters Kluwer Health/Lippincott Williams \& Wilkins.

8. Fernandes, N., van den Heever, J., Hoogendijk, C., Botha, S., Booysen, G., \& Els, J. (2016). Reconstruction of an Extensive Midfacial Defect Using Additive Manufacturing Techniques. J Prosthodont, 25(7), 589-594. doi: 10.1111/jopr.12487.

9. Gebhardt, A., Schmidt, F.M., Hotter, J.S., Sokalla, W., \& Sokalla, P. (2010). Additive manufacturing by selective laser melting the realizer desktop machine and its application for the dental industry. Phys Procedia, 5, 543-549.doi: 10.1016/j.phpro.2010.08.082.

10. Al Mortadi, N., Jones, Q., Eggbeer, D., Lewis, J., \& Williams, R. J. (2015). Fabrication of a resin appliance with alloy components using digital technology without an analog impression. Am J Orthod Dentofacial Orthop, 148(5), 862-867. doi: 10.1016/j.ajodo.2015.06.014. 
11. Carter, S. D., Costa, P. F., Vaquette, C., Ivanovski, S., Hutmacher, D. W., \& Malda, J. (2016). Additive Biomanufacturing: An Advanced Approach for Periodontal Tissue Regeneration. Annals of biomedical engineering, 45(1), 12-22. doi:10.1007/s10439$016-1687-2$

12. Abdulmohsen, B., Parker, S., Braden, M., \& Patel, M. P. (2016). A study to investigate and compare the physicomechanical properties of experimental and commercial temporary crown and bridge materials. Dent Mater, 32(2), 200-210. doi: 10.1016/j.dental.2015.11.025.

13. Hayden, H. C. (2015). Exploration of Materials Used in 3-Dimensional Printing for the Dental Industry. cripps Senior Theses. Paper 577. Available at http://scholarship.claremont.edu/scripps theses/577

14. Peñate, L., Basilio, J., Roig, M., \& Mercade, M. (2015). Comparative study of interim materials for direct fixed dental prostheses and their fabrication with CAD/CAM technique. J Prosthet Dent, 114(2), 248-253. doi: 10.1016/j.prosdent.2014.12.023.

15. Nayar, S., Bhuminathan, S., \& Bhat, W. M. (2015). Rapid prototyping and stereolithography in dentistry. Journal of pharmacy \& bioallied sciences, 7(Suppl 1), S216-S219. doi:10.4103/0975-7406.155913.

16. Anusavice, K. J., Phillips, R. W., Shen, C., \& Rawls, H. R. (2013). Phillips' science of dental materials. St. Louis, Mo: Elsevier/Saunders, pp. 94-108.

17. Stratasys. (2019). 3D printing technologies from Stratasys. Web. Retrieved November 11, 2020 from on https://www.stratasys.com/materials/

18. Khaing, M.W.; Fuh, J.Y.H.; Lu, L. Direct metal laser sintering for rapid tooling: Processing and characterisation of EOS parts. J. Mater. Process. Technol. 2001, 113, 269-272.

19. Dizon, J.R.C.; Espera, A.H., Jr.; Chen, Q.; Advincula, R.C. Mechanical characterization of 3D-printed polymers. Addit. Manuf. 2018, 20, 44-67.

20. Turner, B.N.; Strong, R.; Gold, S.A. A review of melt extrusion additive manufacturing processes: I. Process design and modeling.

Rapid Prototyp. J. 2014, 20, 192-204

21. Patras, M., Naka, O., Doukoudakis, S., \& Pissiotis, A. (2012). Management of Provisional Restorations' Deficiencies: A Literature Review. J. Esthet. Restor. Dent, 4(1):26-38. doi: 10.1111/j.1708-8240.2011.00467.x.

22. Chen, J., Cai, H., Ren, X., Suo, L., Pei, X., \& Wan, Q. (2018). A Systematic Review of the Survival and Complication Rates of AllCeramic Resin-Bonded Fixed Dental Prostheses. J Prosthodont, 27(6), 535-543. doi: 10.1111/jopr.12678.

23. Bajraktarova-Valjakova, E., Korunoska-Stevkovska, V., Kapusevska, B., Gigovski, N., Bajraktarova-Misevska, C., \& Grozdanov, A. (2018). Contemporary Dental Ceramic Materials, A Review: Chemical Composition, Physical and Mechanical Properties, Indications for Use. Open access Macedonian journal of medical sciences, 6(9), 1742-1755. doi:10.3889/oamjms.2018.378.

24. Miyazaki, T., Nakamura, T., Matsumura, H., Ban, S., \& Kobayashi, T. (2013). Current status of zirconia restoration. J Prosthodont Res, 57(4), 236-261. doi: 10.1016/j.jpor.2013.09.001.

25. Guess, P. C., Schultheis, S., Bonfante, E. A., Coelho, P. G., Ferencz, J. L., \& Silva, N. R. (2011). All-ceramic systems: laboratory and clinical performance. Dent Clin North Am, 55(2), 333-352, ix. doi: 10.1016/j.cden.2011.01.005.

26. Della Bona, A., Pecho, O. E., \& Alessandretti, R. (2015). Zirconia as a Dental Biomaterial. Materials (Basel, Switzerland), 8(8), 4978-4991. doi:10.3390/ma8084978.

27. Grandin, H. M., Berner, S., \& Dard, M. (2012). A Review of Titanium Zirconium (TiZr) Alloys for Use in Endosseous Dental Implants. Materials, 5(8), 1348-1360. doi: 10.3390/ma5081348.

28. Della Bona, A., Borba, M., Benetti, P., Pecho, O. E., Alessandretti, R., Mosele, J. C., \& Mores R. T. (2014). Adhesion to dental ceramics. Curr Oral Health Rep, 1(4), 232-238. doi: 10.1007/s40496-014-0030-y.

29. Della Bona, A., Donassollo, T. A., Demarco, F. F., Barrett, A. A., \& Mecholsky, J. J. (2007). Characterization and surface treatment effects on topography of a glass-infiltrated alumina/zirconia-reinforced ceramic. Dent. Mater, 23(6), 769-775. doi: 10.1016/j.dental.2006.06.043.

30. Matinlinna, J. P. (Ed.). (2014). Handbook of Oral Biomaterials. CRC Press. [ebook]. ISBN: 9814463124, 9789814463126; pp. 497500 .

31. Della Bona, A., \& Kelly, J. R. (2008). The clinical success of all-ceramic restorations. J Am Dent Assoc, 139(Suppl 4), 8S-13S.doi: 10.14219/jada.archive.2008.0361.

32. Della Bona, A., Borba, M., Benetti, P., \& Cecchetti, D. (2007). Effect of surface treatments on the bond strength of a zirconiareinforced ceramic to composite resin. Braz Oral Res, 21(1), 10-15. doi: 10.1590/S1806-83242007000100002.

33. Oba, Y., Koizumi, H., Nakayama, D., Ishii, T., Akazawa, N., \& Matsumura, H. (2014). Effect of silane and phosphate primers on the adhesive performance of a tri-n-butylborane initiated luting agent bonded to zirconia. Dent Mater J, 33(2), 226-232. doi: 10.4012/dmj.2013-346.

34. Kim, S. H., \& Watts, D. C. (2007). In vitro study of edge-strength of provisional polymer-based crown and fixed partial denture materials. Dent Mater, 23(12), 1570-1573. doi: 10.1016/j.dental.2007.06.023.

35. Karaokutan, I., Sayin, G., \& Kara, O. (2015). In vitro study of fracture strength of provisional crown materials. The Journal of Advanced Prosthodontics, 7(1), 27-31. doi:10.4047/jap.2015.7.1.27.

36. Alp, G., Murat, S., \& Yilmaz, B. (2019). Comparison of Flexural Strength of Different CAD/CAM PMMA-Based Polymers. J. Prosthodont, 28(2), e491-e495. doi: 10.1111/jopr.12755.

37. Cha, M. S., Lee, S. W., Huh, Y. H., Cho, L. R., \& Park, C. J. (2017). Metal stain on monolithic zirconia restoration: A case report. The journal of advanced prosthodontics, 9(2), 138-142. doi:10.4047/jap.2017.9.2.138

38. Park, J. M., Ahn, J. S., Cha, H. S., \& Lee, J. H. (2018). Wear Resistance of 3D Printing Resin Material Opposing Zirconia and Metal Antagonists. Materials (Basel, Switzerland), 11(6), 1043. doi:10.3390/ma11061043 
39. Astudillo-Rubio, D., Delgado-Gaete, A., \& Bellot-Arcõ̂̂s, C., et al. (2018). Mechanical properties of provisional dental materials: A systematic review and meta-analysis. PLoS ONE, 13(2), e0193162. doi: 10.1371/journal.pone.0193162.

40. Bhargav, A., Sanjairaj, V., Rosa, V., Feng, L. W., \& Fuh YH, J. (2018). Applications of additive manufacturing in dentistry: A review. J Biomed Mater Res B Appl Biomater, 106(5), 2058-2064. doi: 10.1002/jbm.b.33961.

41. Revilla-León, M, Gonzalez-Martín, Ó., Pérez López, J., Sánchez-Rubio, J. L., \& Özcan, M. (2017). Position Accuracy of Implant Analogs on 3D Printed Polymer versus Conventional Dental Stone Casts Measured Using a Coordinate Measuring Machine. J Prosthodont, 27(6), 560-567. doi: 10.1111/jopr.12708.

42. Kim, S. H., \& Watts, D. C. (2004). Effect of glass-fiber reinforcement and water storage on fracture toughness (KIC) of polymerbased provisional crown and FPD materials. Int J Prosthodont, 17(3), 318-322.

43. Hamza, T. A, Johnston, W. M., \& Schricker, S. R. (2014). Effect of polyhedral silsesquioxane (POSS) on the flexural strength and color of interim materials. J Prosthet Dent, 112(2), 228-234. doi: 10.1016/j.prosdent.2014.01.008.

44. Nayar, S., Ganesh, R., \& Santhosh, S. (2015). Fiber reinforced composites in prosthodontics - A systematic review. Journal of pharmacy \& bioallied sciences, 7(Suppl 1), S220-S222. doi:10.4103/0975-7406.155914

45. Gopichander, N., Halini Kumarai, K. V., \& Vasanthakumar, M. (2015). Effect of polyester fiber reinforcement on the mechanical properties of interim fixed partial dentures. The Saudi dental journal, 27(4), 194-200. doi:10.1016/j.sdentj.2015.03.002.

46. Formlabs Flickr images. Retrieved November 11, 2020 from on www,formlabs.com/industries/dentistry/ 